\title{
Strychnine poisoning due to traditional Chinese medicine: a
}

\section{case series [version 1; peer review: 1 approved, 1 approved with reservations]}

\author{
Hok-Fung Tong, Candace Yim Chan, Sau-Wah Ng, Tony Wing-Lai Mak
}

Hospital Authority Toxicology Reference Laboratory, Princess Margaret Hospital, Hospital Authority, Hong Kong

\author{
V1 First published: 15 Sep 2021, 10:924 \\ https://doi.org/10.12688/f1000research.73072.1 \\ Latest published: 17 Dec 2021, 10:924 \\ https://doi.org/10.12688/f1000research.73072.2
}

\section{Abstract}

Background: Strychnine poisoning is rare but possibly fatal. The most reported sources of strychnine poisoning include rodenticides and adulterated street heroin. Here we report a case series of an unusual cause of strychnine poisoning - Strychni semen, a herb known as "maqianzi" in traditional Chinese medicine (TCM).

Methods: All cases of strychnine poisoning confirmed by the Hospital Authority Toxicology Reference Laboratory (HATRL, the highest-level clinical toxicology laboratory in Hong Kong) between May 2005 and May 2018 were reviewed.

Results: Twelve cases of strychnine poisoning were recorded, and Strychni semen was the exclusive source. Ten (83.3\%) patients presented with muscle spasms, and four (33.3\%) developed typical conscious convulsions. The poisoning was severe in two (16.7\%) patients, moderate in three (25\%) and mild in eight $(58.3 \%)$. No case fatality was recorded. Three (25\%) patients were TCM practitioners and two (16.7\%) were laymen who bought the herb themselves without a proper prescription.

Conclusion: The practice of TCM is becoming popular in different parts of the world amid the COVID-19 pandemic. The spectrum of clinical features of strychnine poisoning secondary to Strychni semen are similar to those arising from different origins. Eliciting a history of TCM use, apart from exposure to rodenticides and drugs of abuse, may allow timely diagnosis in patients with compatible clinical features. Enhancement of TCM safety could minimize the hazard.

Keywords

Strychnine poisoning, herbal medicine poisoning, Strychni semen, Maqianzi

\section{Open Peer Review}

Approval Status

1 2

version 2

(revision)

17 Dec 2021

version 1

15 Sep 2021

view
view
$?$

1. Jou-Fang Deng, Taipei Veterans General Hospital, Taipei, Taiwan

2. Camille Paradis (iD, Centre Hospitalier

Universitaire de Bordeaux, Bordeaux, France Any reports and responses or comments on the article can be found at the end of the article. 
Corresponding author: Tony Wing-Lai Mak (twlmak@gmail.com)

Author roles: Tong HF: Conceptualization, Data Curation, Formal Analysis, Investigation, Methodology, Writing - Original Draft Preparation; Chan CY: Data Curation, Project Administration; Ng SW: Data Curation, Formal Analysis, Investigation, Validation; Mak TWL : Conceptualization, Data Curation, Formal Analysis, Investigation, Methodology, Project Administration, Supervision, Writing - Review \& Editing

Competing interests: No competing interests were disclosed.

Grant information: The author(s) declared that no grants were involved in supporting this work.

Copyright: ( 2021 Tong HF et al. This is an open access article distributed under the terms of the Creative Commons Attribution License, which permits unrestricted use, distribution, and reproduction in any medium, provided the original work is properly cited.

How to cite this article: Tong HF, Chan CY, Ng SW and Mak TWL. Strychnine poisoning due to traditional Chinese medicine: a case series [version 1; peer review: 1 approved, 1 approved with reservations] F1000Research 2021, 10:924

https://doi.org/10.12688/f1000research.73072.1

First published: 15 Sep 2021, 10:924 https://doi.org/10.12688/f1000research.73072.1 


\section{Background}

Around a century ago, the wide availability of strychnine as an over-the-counter remedy for a variety of ailments caused a significant number of deaths, especially in children ${ }^{1}$. As such, strychnine has been withdrawn from the food and medicine markets in many countries, and poisoning is now rare. Nowadays, the most reported sources of poisoning include rodenticides ${ }^{2,3}$ and adulterated street heroin ${ }^{4,5}$, where strychnine was added to increase the heroin retention when it volatized ${ }^{6}$.

Strychni semen, a herb also known as "maqianzi" in traditional Chinese medicine (TCM), also contains strychnine together with its less toxic analog, brucine. The herb is used for its analgesic, anti-diarrheal, antioxidant, anti-inflammatory, anti-microbial and anti-neoplastic properties ${ }^{7,8}$. However, it has an apparently narrow therapeutic index - the recommended dosage is $0.3-0.6 \mathrm{~g}$ daily according to the Chinese Pharmacopoeia $2015^{9}$.

Strychnine is rapidly absorbed from the gastrointestinal tract and toxicity may occur as soon as 15 minutes after ingestion. By inhibition of glycine receptors at the spinal cord, strychnine overdose causes weakness and intermittent spasms. Each episode of spasm lasts for around half to two minutes and is easily triggered by emotional distress or even trivial sensory stimuli $^{10}$. Severe spasms may mimic epileptic convulsions, but there is preserved awareness without post-ictal drowsiness. This typical feature of strychnine poisoning is known as conscious convulsions/spinal seizures ${ }^{11}$ and may mimic tetanus, though the latter can be differentiated by a positive history of injury, and a more gradual and protracted course of illness ${ }^{12}$. Severe convulsions may cause rhabdomyolysis and can be rapidly fatal due to respiratory failure ${ }^{13}$. Milder symptoms of strychnine poisoning include agitation, palpitations, hyperventilation, dizziness, hyperacusis and paresthesia ${ }^{14}$.

Apart from epilepsy and tetanus, acute dystonia and hypocalcemia are the other differential diagnoses of strychnine poisoning. In acute dystonia, muscle contractions are more static. Hypocalcemia also results in numbness and muscle spasms but can be easily differentiated by blood tests ${ }^{15}$.

Management of strychnine poisoning is supportive. Activated charcoal may be given if patients present early. Benzodiazepines are used to control muscle spasms, and a dark and quiet environment also helps. Airway intervention and mechanical ventilation can be lifesaving, though succinylcholine must be avoided as it exacerbates muscle spasms ${ }^{15-17}$.

Here we report a case series of an unusual cause of strychnine poisoning - Strychni semen.

\section{Methods}

All cases of strychnine poisoning, which were analytically confirmed by the Hospital Authority Toxicology Reference Laboratory (HATRL), between May 2005 and May 2018 were reviewed. HATRL is the highest-level clinical toxicology laboratory serving all public hospitals in Hong Kong, and analysis of suspected herbal poisoning is one of the unique services provided by the laboratory. Clinical records were reviewed to collect the patient demographics, details of exposure, clinical features, pertinent laboratory findings, treatment provided and clinical outcomes.

Diagnosis of strychnine poisoning was confirmed by detection of strychnine in urine, and Strychni semen exposure was inferred by the concurrent detection of brucine. Detection of strychnine and brucine was performed by using high-performance liquid chromatography with diode array detection (HPLCDAD; Agilent 1100 and 1200 LC Systems with DAD) and liquid chromatography-tandem mass spectrometry (LC-MS/MS; Agilent 1100 LC System with Applied Biosystems 4000 QTrap triple-quadruple mass spectrometer ${ }^{18}$. Wherever available, herbal prescriptions were transcribed and studied, unused herbs were morphologically identified, and analysis of strychnine and brucine was performed on suspicious herbal products.

\section{Results}

There were twelve cases of strychnine poisoning confirmed during the study period, and all of them were due to Strychni semen (Table 1). Two severe cases are further described to highlight the salient features.

A 55-year-old male (case 5 in Table 1), a TCM practitioner, was woken up by severe wrist pain at night and inadvertently took 19 grams (31 times the recommended therapeutic dosage) of Strychni semen instead of another herb. He developed dizziness, hyperventilation, generalized muscle spasms and conscious convulsions 30 minutes later. He attended the accident \& emergency department and was hospitalized. Activated charcoal and intravenous diazepam ( $3 \mathrm{mg}$ ) were given, and the symptoms subsided six hours later. However, there was rhabdomyolysis (plasma creatine kinase level 5085 U/L; reference interval 45-235 U/L) and he required prolonged aggressive rehydration. Strychni semen exposure was confirmed by detection of both strychnine and brucine in urine. He eventually recovered and was discharged after one week of admission.

A 45-year-old man (case 7 in Table 1) consulted a bone setter for gouty arthritis and was dispensed some herbal powder with undisclosed ingredients. One hour after taking the herbal powder, he developed chest discomfort, dyspnea, hyperacusis, generalized muscle spasms, trismus, opisthotonus and conscious convulsions. He was hospitalized and repeated dosing of intravenous diazepam (10 $\mathrm{mg}$ in total) was required to control the convulsions. The symptoms lasted for seven hours, but he soon requested early discharge despite medical advice. Strychni semen exposure was subsequently analytically confirmed.

The demographics and clinical features of all 12 patients are summarized in Table 1 in chronological order of presentation. Numbers of male and female patients were equal. The median age was 48.5 years (range $8-58$ years). Strychni semen exposure was the exclusive source of strychnine poisoning, and the herb was most commonly used to relieve chronic pain. 
Table 1. Summary of patient demographics and clinical features.

\begin{tabular}{|c|c|c|c|c|c|c|c|c|}
\hline Case & Sex & Age (y) & $\begin{array}{l}\text { Latent } \\
\text { period (hrs) }\end{array}$ & $\begin{array}{l}\text { Symptom } \\
\text { duration (hrs) }\end{array}$ & Weakness & Spasm & Convulsion & Other manifestations \\
\hline 1 & M & 58 & 0.5 & 4.5 & - & - & - & $\begin{array}{l}\text { Agitation, palpitations, dizziness, } \\
\text { paresthesia }\end{array}$ \\
\hline $2^{b}$ & M & 52 & 0.6 & 1.0 & + & + & - & Not reported \\
\hline 3 & $\mathrm{~F}$ & 36 & 2.0 & 4.0 & + & + & - & Not reported \\
\hline $\mathbf{4}^{\mathrm{b}}$ & M & 32 & 0.5 & 0.5 & + & + & - & Palpitations, dizziness \\
\hline $\mathbf{5}^{*, b}$ & M & 55 & 0.5 & 6.0 & + & + & + & Dizziness, hyperventilation \\
\hline \multirow[t]{2}{*}{$6^{a}$} & $\mathrm{~F}$ & 8 & 0.5 & 0.5 & + & - & - & Paresthesia \\
\hline & & & 0.2 & 1.3 & + & + & - & Dizziness, paresthesia \\
\hline 7 & M & 45 & 1.0 & 7.0 & + & + & + & $\begin{array}{l}\text { Dyspnea, paresthesia, dizziness, } \\
\text { hyperacusis }\end{array}$ \\
\hline \multirow[t]{2}{*}{$\mathbf{8}^{\mathrm{a}, \mathrm{c}}$} & $\mathrm{F}$ & 54 & 2.0 & N/A & - & + & - & Dizziness \\
\hline & & & 2.0 & 6.0 & + & + & + & Vomiting, dizziness \\
\hline 9 & $\mathrm{~F}$ & 36 & 0.3 & 3.0 & + & + & + & Palpitations \\
\hline \multirow[t]{2}{*}{$10^{2}$} & M & 49 & N/A & 3.0 & - & - & - & Chest pain, dyspnea \\
\hline & & & 1.0 & 3.0 & - & - & - & $\begin{array}{l}\text { Chest pain, dyspnea, respiratory } \\
\text { acidosis }\end{array}$ \\
\hline 11 & $\mathrm{~F}$ & 55 & 0.5 & 6.0 & - & + & - & Paresthesia \\
\hline \multirow[t]{2}{*}{$12^{a}$} & $\mathrm{~F}$ & 48 & 0.5 & 3.0 & - & + & - & Palpitations, dyspnea \\
\hline & & & 2.0 & 3.0 & + & + & - & Palpitations, dyspnea \\
\hline \multicolumn{9}{|c|}{ *: Severe poisoning (see text for description) } \\
\hline \multicolumn{9}{|c|}{ a: Recurrent episodes of poisoning } \\
\hline \multicolumn{9}{|c|}{$\mathrm{b}:$ This patient was a TCM practitioner } \\
\hline \multicolumn{9}{|c|}{ c: This patient was a layman who bought the herb from a TCM pharmacy } \\
\hline \multicolumn{9}{|c|}{ +: Present } \\
\hline \multicolumn{9}{|c|}{$\therefore$ Absent } \\
\hline
\end{tabular}

Four $(33.3 \%)$ patients had recurrent episodes of poisoning before the definite diagnosis was made. Ten (83.3\%) patients presented with muscle spasms, and four (33.3\%) patients developed typical conscious convulsions. One patient (case 10) had transient respiratory acidosis, which resolved spontaneously. Median latent period before symptom onset was 0.5 hours (range $0.2-2$ hours), and the median symptom duration was 3.5 hours (range $0.5-7$ hours). Based on a previously published poisoning severity score system ${ }^{19}$, the poisoning was severe in two $(16.7 \%)$ patients, moderate in three $(25 \%)$ and mild in seven $(58.3 \%)$. No case fatality was recorded, and all patients recovered eventually.

Intriguingly, three $(25 \%)$ patients were professional TCM practitioners (cases 2, 4, 5) themselves. On the other hand, two (16.7\%) were laymen who bought Strychni semen without a proper prescription. One was a housewife (case 8) who bought the herb at a Chinese medicine pharmacy and took a markedly excessive dose (15 times the recommended dosage) of Strychni semen based on a misprinted soup recipe in a book borrowed from a public library ${ }^{20}$.

\section{Discussion}

Our results showed that Strychni semen was the exclusive source of clinically and analytically confirmed strychnine poisoning in Hong Kong during the 14-year study period. In addition, Strychni semen poisoning shared a similar spectrum of clinical features with strychnine poisoning due to other causes $^{1,10,11,15,16,21}$. This peculiarly predominant source of strychnine poisoning in Hong Kong is likely contributed to by the fact that most Hong Kong residents are ethnic Chinese.

Nevertheless, with globalization, immigration and the rising popularity of TCM around the world ${ }^{22}$, especially amid the COVID-19 pandemic ${ }^{23}$, eliciting a history of herbal medicine use, in addition to exposure to rodenticides and drugs of abuse, 
may be helpful in making the clinical diagnosis of strychnine poisoning. Identifying the source of strychnine poisoning is also important for public health measures.

Unfortunately, obtaining a definite history of Strychni semen use can be challenging if the herbal prescription is not disclosed by the TCM practitioner. In our case series, five (41.6\%) patients did not possess such information, which made the diagnosis difficult. We believe that empowering patients in the therapeutic process by disclosing the herbal prescription can only be beneficial, as the value of this safety enhancement step has been unquestionably exemplified by Western medicine professionals for decades. We noted that TCM clinics associated with the Hospital Authority and the universities in Hong Kong provide computer-generated herbal prescriptions to their patients. However, this good practice is neither universally exercised nor required legally.

Intriguingly, three patients of our case series were TCM practitioners themselves, who were the learned professionals of this dangerous herb. This illustrates the fact that Strychni semen is a dangerous herb and systematic measures should be introduced to minimize such poisoning events.

Enhancement in TCM dispensing could be an important measure. Among our case series, the TCM dispensers did not prevent the inappropriate dosages of Strychni semen from being prescribed by the TCM practitioners. Shockingly, Strychni semen was dispensed to two patients (case $1 \& 8$ ) who did not bear a registered TCM practitioner's prescription. These suboptimal practices should certainly be noted and enhanced by the profession. To ensure patient safety, both good prescription and dispensing practices are essential. In the long run, all TCM practitioners and dispensers around the world should be adequately trained, certified and licensed.

\section{Conclusion}

The practice of TCM is becoming popular in different parts of the world amid the COVID-19 pandemic. This study serves to remind the profession that strychnine poisoning can result from TCM use. The spectrum of clinical features of strychnine poisoning secondary to Strychni semen (maqianzi) are similar to those that arise from different origins. Eliciting a history of TCM use, apart from exposure to rodenticides and drugs of abuse, may allow timely diagnosis in patients with compatible clinical features. Enhancement of TCM safety could minimize the hazard.

\section{Consent}

We respected all patients' rights to privacy and protected their identity. The study was approved by the Kowloon West Cluster Research Ethics Committee of the Hospital Authority, Hong Kong (approval number KW/EX-19-002), who waived the need for informed consent as the presented data have been anonymized and de-identified.
1. Aikman J: Strychnine Poisoning in Children. J Am Med Assoc. 1930; 95(22): 1661-5.

Publisher Full Text

2. Cantrell FL: Look What I Found! Poison Hunting on eBay®. Clin Toxicol (Phila). 2005; 43(5): 375-9.

PubMed Abstract | Publisher Full Text

3. Lindsey $T$, O'Hara J, Irvine $R$, et al.: Strychnine Overdose Following Ingestion of Gopher Bait. J Anal Toxicol. 2004; 28(2): 135-7. PubMed Abstract | Publisher Full Text

4. Decker WJ, Baker HE, Tamulinas SH: Two deaths resulting from apparent parenteral injection of strychnine. Vet Hum Toxicol. 1982; 24(2): 86. PubMed Abstract

5. O'Callaghan WG, Joyce $\mathrm{N}$, Counihan $\mathrm{HE}$, et al.: Unusual strychnine poisoning and its treatment: report of eight cases. Br Med J (Clin Res Ed). 1982; 285(6340): 478.

PubMed Abstract | Publisher Full Text | Free Full Text

6. Cole $C$, Jones $L$, McVeigh J, et al.: Adulterants in illicit drugs: a review of empirical evidence. Drug Test Anal. 2011; 3(2): 89-96. PubMed Abstract | Publisher Full Text

7. Patel K, Laloo D, Singh GK, et al.: A review on medicinal uses, analytical techniques and pharmacological activities of Strychnos nux-vomica Linn.: A concise report. Chin J Integr Med. 2017; 1-13. PubMed Abstract | Publisher Full Text

8. Guo R, Wang T, Zhou G, et al.: Botany, Phytochemistry, Pharmacology and Toxicity of Strychnos nux-vomica L.: A Review. Am J Chin Med. 2018; 46(1): $1-23$.

PubMed Abstract | Publisher Full Text

9. State Pharmacopoeia Commision: Pharmacopoeia of the People's Republic of China 2015. 1st ed. Beijing, China: China Medical Science Press; 2015. Reference Source
10. Oberpaur B, Donoso A, Clavería C, et al:: Strychnine poisoning: an uncommon intoxication in children. Pediatr Emerg Care. 1999; 15(4): 264-5. PubMed Abstract

11. Flood RG: Strychnine poisoning. Pediatr Emerg Care. 1999; 15(4): 286-7. PubMed Abstract

12. Philippe G, Angenot L, Tits M, et al:: About the toxicity of some Strychnos species and their alkaloids. Toxicon. 2004; 44(4): 405-16. PubMed Abstract | Publisher Full Text

13. Heiser JM, Daya MR, Magnussen AR, et al.: Massive strychnine intoxication: Serial blood levels in a fatal case. Clin Toxicol. 1992; 30(2): 269-83. PubMed Abstract | Publisher Full Text

14. Caspary DM, Pazara KE, Ko"ssI M, et al.: Strychnine alters the fusiform cell output from the dorsal cochlear nucleus. Brain Res. 1987; 417(2): 273-82. Publisher Full Text

15. Nelson L, Hoffman R, Howland MA, et al:: Goldfrank's Toxicologic Emergencies. Eleventh Edition. 11th Edition. New York: McGraw-Hill Education / Medical; 2019. Reference Source

16. Jackson G, Ng SH, Diggle GE, et al.: Strychnine poisoning treated successfully with diazepam. Br Med J. 1971; 3(5773): 519-20. PubMed Abstract | Publisher Full Text | Free Full Text

17. Lambert JR, Byrick RJ, Hammeke MD: Management of acute strychnine poisoning. Can Med Assoc J. 1981; 124(10): 1268-70. PubMed Abstract | Free Full Text

18. Ng SW, Ching CK, Chan AYW, et al:: Simultaneous detection of $\mathbf{2 2}$ toxic plant alkaloids (aconitum alkaloids, solanaceous tropane alkaloids, sophora alkaloids, strychnos alkaloids and colchicine) in human urine and herbal samples using liquid chromatography-tandem mass spectrometry. J Chromatogr B Analyt Technol Biomed Life Sci. 2013; 942-943: 63-9. PubMed Abstract | Publisher Full Text 
19. Persson HE, Sjöberg GK, Haines JA, et al.: Poisoning Severity Score. Grading of Acute Poisoning. J Toxicol Clin Toxicol. 1998; 36(3): 205-13.

PubMed Abstract | Publisher Full Text

20. Chong YK, Ching CK, Ng SW, et al.: Recipes and general herbal formulae in books: causes of herbal poisoning. Hong Kong Med J. 2014; 20(4): 343-6. PubMed Abstract | Publisher Full Text

21. Katz J, Prescott K, Woolf AD: Strychnine poisoning from a Cambodian traditional remedy. Am J Emerg Med. 1996; 14(5): 475-7.

PubMed Abstract | Publisher Full Text

22. Cyranoski D: THE BIG PUSH FOR CHINESE MEDICINE. Nature. 2018; 561: 448-50.

23. Ren J, Zhang AH, Wang XJ: Traditional Chinese medicine for COVID-19 treatment. Pharmacol Res. 2020; 155: 104743.

PubMed Abstract | Publisher Full Text | Free Full Text 


\section{Open Peer Review}

\section{Current Peer Review Status:}

\section{Version 1}

Reviewer Report 06 December 2021

https://doi.org/10.5256/f1000research.76695.r101016

(C) 2021 Paradis C. This is an open access peer review report distributed under the terms of the Creative Commons Attribution License, which permits unrestricted use, distribution, and reproduction in any medium, provided the original work is properly cited.

\section{Camille Paradis}

Centre Hospitalier Universitaire de Bordeaux, Bordeaux, France

This is a retrospective case series. This work is very interesting since it presents a circumstance of exposure to strychnine by therapeutic error, which is unusual compared to the numerous cases of intoxication in the context of suicidal behavior or other involuntary circumstances. This has implications for the management of intoxicated patients because this circumstance does not raise suspicion of this type of xenobiotic.

For the context, I find that the reason for the use of strychnine as a heroin adulterant is not easy to understand. If it is difficult to explain it quickly, perhaps it would be better to just mention this use, without detailing its origin. The bibliographic reference can remain the same. Secondly, I did not really understand why the term "weakness" was used for the description of strychnine poisoning. Classically, patients present with a state of hyperexcitability with significant rigidity, perhaps you meant to refer to the symptom "coma" by this term? If you change it, consider doing so in Table 1 as well.

Regarding the data shared on your case series, do you have any notion of the amounts of strychnine and brucine found in the urine of your patients? If you have them, it would be a pity not to share them, especially to compare them with the rest of the literature. In addition, it might be interesting to provide the dates of each case of intoxication, perhaps in your table. Actually, you indicate that the use of TCM is increasing, it might be interesting to see how the number of intoxications evolve over the duration of your study.

For the discussion, I really have trouble seeing how you conclude that Strychni semen poisonings are the only circumstances of strychnine poisonings in your study location. It is possible that you have other arguments for stating this, but they need to be included in your paper. In particular, you should explicitly state that no center other than HATRL can analytically confirm strychnine poisoning in your study location. In a recently published study by Paradis et al., ${ }^{1}$ it is shown that cases of strychnine poisoning still occur through old rodenticide products. Then I find the sentence that starts with "We believe that empowering patients..." perhaps a bit long and I find it difficult to easily understand its purpose. 
Finally, two formal remarks. On the bibliography, you specify "Clin Toxicol (Phila)" (2) and "Clin Toxicol" alone (13), check that there is not a clarification to be made on which one is alone. For the expression of all your values as a percentage, it seems to me that for a number of patients $<100$ you should express your values as integers and not as decimal numbers.

For the conclusion, I find it perfectly appropriate with a clear purpose, its opening is particularly valid.

\section{References}

1. Paradis C, Dondia D, Nardon A, Blanc-Brisset I, et al.: Strychnine, old still actual poison: description of poisoning cases reported to French Poison Control Centers over the past thirteen years. Toxin Reviews. 2021. 1-7 Publisher Full Text

Is the background of the cases' history and progression described in sufficient detail? Partly

Are enough details provided of any physical examination and diagnostic tests, treatment given and outcomes?

Partly

Is sufficient discussion included of the importance of the findings and their relevance to future understanding of disease processes, diagnosis or treatment?

Partly

Is the conclusion balanced and justified on the basis of the findings?

Yes

Competing Interests: No competing interests were disclosed.

Reviewer Expertise: Pharmacy, Clinical Toxicology

I confirm that I have read this submission and believe that I have an appropriate level of expertise to confirm that it is of an acceptable scientific standard, however I have significant reservations, as outlined above.

Author Response 09 Dec 2021

Hok Fung Tong,

Thank you very much for your comments and suggestions on improving the quality of the manuscript. Please kindly find below our responses.

1) For context, I find that the reason for the use of strychnine as a heroin adulterant is not easy to understand. If it is difficult to explain it quickly, perhaps it would be better to just mention this use, without detailing its origin. The bibliographic reference can remain the same. 
- The reason has been removed.

2) I did not really understand why the term "weakness" was used for the description of strychnine poisoning. Classically, patients present with a state of hyperexcitability with significant rigidity, perhaps you meant to refer to the symptom "coma" by this term? If you change it, consider doing so in Table 1 as well.

- We replaced the term "weakness" with "stiffness" instead as this should be the more appropriate description, although some patients would describe such symptom as "weak".

3) Regarding the data shared on your case series, do you have any notion of the amounts of strychnine and brucine found in the urine of your patients? If you have them, it would be a pity not to share them, especially to compare them with the rest of the literature.

- Our laboratory did not provide quantitative analyses of strychnine and brucine. Therefore, such information is not available.

4) In addition, it might be interesting to provide the dates of each case of intoxication, perhaps in your table. Actually, you indicate that the use of TCM is increasing, it might be interesting to see how the number of intoxications evolve over the duration of your study.

- We have added the years of clinical presentation in Table 1.

5) For the discussion, I really have trouble seeing how you conclude that Strychni semen poisonings are the only circumstances of strychnine poisonings in your study location. It is possible that you have other arguments for stating this, but they need to be included in your paper. In particular, you should explicitly state that no center other than HATRL can analytically confirm strychnine poisoning in your study location.

- Being the highest level clinical toxicology laboratory in Hong Kong, HATRL is the only laboratory which provides analytical confirmation for strychnine poisoning locally. For all analytically confirmed strychnine poisoning cases that we have encountered during the study period, they were all due to Strychni semen. Such information is now stated in the methods section.

6) In a recently published study by Paradis et al., it is shown that cases of strychnine poisoning still occur through old rodenticide products.

- We agree that strychnine poisoning can still occur through rodenticides, and have added the citation of this study in the introduction section.

7) Then I find the sentence that starts with "We believe that empowering patients..." perhaps a bit long and I find it difficult to easily understand its purpose.

- We have removed the sentence. 
8) Finally, two formal remarks. On the bibliography, you specify "Clin Toxicol (Phila)" (2) and "Clin Toxicol" alone (13), check that there is not a clarification to be made on which one is alone. For the expression of all your values as a percentage, it seems to me that for a number of patients $<100$ you should express your values as integers and not as decimal numbers.

- We have unified the references as "Clin Toxicol", and have modified the percentages accordingly.

Competing Interests: No competing interests were disclosed.

Reviewer Report 29 September 2021

https://doi.org/10.5256/f1000research.76695.r94448

(C) 2021 Deng J. This is an open access peer review report distributed under the terms of the Creative Commons Attribution License, which permits unrestricted use, distribution, and reproduction in any medium, provided the original work is properly cited.

\section{Jou-Fang Deng}

Division of Clinical Toxicology and Occupational Medicine, Department of Medicine, Taipei Veterans General Hospital, Taipei, Taiwan

I am a medical toxicologist having been in practice since 1982. Many years ago, I used to treat severe convulsion cases related to events of drug abuse, which ended up with a diagnosis of strychnine poisoning confirmed by a clinical toxicology laboratory. However, strychnine poisoning related to the use of traditional medicine is not what I am familiar with, and as it is described in the article, it indeed may potentially occur in our society, in which the practice of traditional medicine is not well regulated.

Strychnine poisoning could be a life-threatening condition, and without appropriate treatment and timely ventilation support, life can disappear quickly. This article has brought up some important points, relevant to both the societies of traditional medicine and western medicine. Since strychnine itself does possess prominent toxicity, to prevent any unnecessary and avoidable poisoning, I would like to propose that the dispensing of strychnine contented herbs should not continue, given its toxic potential.

This article describes a retrospective study of a collection of unusual cases of strychnine poisoning which need to be remembered in general practice as well as emergency settings. This is a very interesting clinical report and is valuable for the clinical doctors. Since it is a well written article, and clearly demonstrates the importance of the history of herb intake in our daily practice, I would recommend that there is no need for any revision.

Is the background of the cases' history and progression described in sufficient detail? 
Yes

Are enough details provided of any physical examination and diagnostic tests, treatment given and outcomes?

Yes

Is sufficient discussion included of the importance of the findings and their relevance to future understanding of disease processes, diagnosis or treatment?

Yes

Is the conclusion balanced and justified on the basis of the findings?

Yes

Competing Interests: No competing interests were disclosed.

Reviewer Expertise: Medical toxicologist

I confirm that I have read this submission and believe that I have an appropriate level of expertise to confirm that it is of an acceptable scientific standard.

The benefits of publishing with F1000Research:

- Your article is published within days, with no editorial bias

- You can publish traditional articles, null/negative results, case reports, data notes and more

- The peer review process is transparent and collaborative

- Your article is indexed in PubMed after passing peer review

- Dedicated customer support at every stage

For pre-submission enquiries, contact research@f1000.com

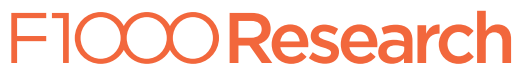

